\title{
Telenovelas turcas en el canal temático digital Nova: nuevos horizontes narrativos y de programación
}

Turkish soap operas on digital thematic channel Nova: new narrative and programming horizons

Tatiana Hidalgo-Marí

Jesús Segarra-Saavedra
Universidad de Alicante

tatiana.hidalgo@ua.es

https://orcid.org/0000-0003-4599-5876

Universidad de Alicante

jesus.segarra@ua.es

https://orcid.org/0000-0001-9420-5258 


\section{Resumen}

Este artículo tiene como objetivo proporcionar una taxonomía sobre la telenovela turca emitida en el canal temático español Nova, con el fin de determinar nuevas estrategias y narrativas en tendencia. Para ello, se combina una metodología cualitativa con el análisis del discurso que ofrece resultados sobre las diferencias y similitudes entre la telenovela turca y latinoamericana y permite detectar tendencias que están contribuyendo al posicionamiento del producto narrativo en cuestión.

Palabras clave: Cultura; Comunicación; Narración; Telenovela; Televisión; Ficción televisiva; Serie de televisión.

\section{Abstract}

This paper aims to provide a taxonomy on the Turkish soap opera issued on the Spanish thematic channel Nova, in order to determine new strategies and narratives in trend. For this, a qualitative methodology is combined with the discourse analysis that offers results on the differences and similarities between the Turkish and Latin American soap opera and allows trends that are contributing to the positioning of the narrative product in question.

Keywords: Culture; Communication; Narration; Soap opera; Television; Television fiction; Television series.

\section{Introducción}

La telenovela turca se ha postulado, en los últimos años, como un producto de ficción televisivo de éxito, que está gozando de muy buena acogida tanto en los países europeos como en América Latina. Estudios recientes sitúan al país otomano como el segundo exportador de ficción televisiva del mundo, superando a países como México o Brasil, punteros en la exportación de telenovelas (Camille, 2018). La WIT (World Information Tracking) señaló cinco tendencias en el mercado televisivo internacional, entre las que destacan las tramas universales, ejemplificadas por el incipiente éxito de las novelas turcas, en especial, en América Latina y España.

Desde que en el año 2007 la productora MBC emitiera la telenovela Iklil al-ward, las series turcas han tenido un éxito abrumador en el mundo árabe que rápidamente se extendió por América Latina, Europa y Asia (Molina, 2013). No obstante, a principios de los años noventa, el cambio en el paradigma comunicativo de la sociedad turca quedaba patente, gracias lo que Akin denominó la apertura de "la caja mágica de Pandora" (Akin, 2009), es decir, la irrupción de canales comerciales de televisión que, poco a poco, fueron redefiniendo el consumo televisivo y las preferencias socioculturales tanto de los espectadores como de los consumidores (Ozbek 1991; Stokes, 1992). Hasta la apertura del mercado televisivo en los años noventa, la ficción nacional turca se había centrado en la adaptación de novelas clásicas y la adaptación de miniseries de televisión históricas por parte de la TRT, el canal público y nacional del país. En el año 1999, la exportación 
internacional de la ficción Deli Yürek marcó una nueva forma de producir, desvelando el éxito que las ficciones turcas generaban fuera de las fronteras nacionales. Junto a este fenómeno, la irrupción de las cadenas comerciales trajo consigo una inversión sin precedentes en producto seriado de ficción.

Akin (2011) ya apuntaba que, en los años previos a sus estudios, prácticamente todos los canales de televisión turcos emitían una o dos series anuales de producción propia, que obtenían gran popularidad entre la audiencia. La exportación inicial se centró en países vecinos de Asia Central, incluidos Kazajstán y Uzbekistán, donde los países comparten un origen étnico común con Turquía y rápidamente se ha extendido a una amplia gama de países, incluidos todos los países del Medio Oriente y África del Norte, Asia Central y varios países de Europa del Este: Bulgaria, Grecia, Rumania, Eslovenia, Eslovaquia, Hungría, Ucrania, Moldavia, Serbia, Macedonia y Rusia (Balli, Balli \& Cereci, 2013). Todos estos flujos de exportación suscitaron el interés por los productores, que aumentaron la inversión en este producto televisivo en vista de la rentabilidad capaz de aportar tanto dentro como fuera del país, debido, entre otros factores, al coste inferior de producción en comparación con los costes de producción en países tradicionalmente exportadores de telenovelas.

La llegada de la telenovela turca a América Latina y Estados Unidos supone un fenómeno sin precedentes, especialmente si se tiene en cuenta que son los países de esta zona los padres del género, la cuna desde la que se han exportado la gran mayoría de telenovelas producidas desde los orígenes de la televisión. En canales como Mega (Chile) o Telefé (Argentina) alrededor de la mitad de la ficción seriada de la parrilla corresponde a telenovelas turcas, un fenómeno que, de forma más tímida pero latente se está replicando en España, en canales como Nova (Grupo Atresmedia) o Divinity (Grupo Mediaset).

Ante este fenómeno, el presente trabajo tiene como objetivo analizar la llegada de la telenovela turca a España, a partir de un estudio taxonómico que analiza las características de dicha ficción televisiva emitida en este país. En concreto, se estudia la irrupción de la telenovela turca en el canal Nova del grupo español Atresmedia y el cambio de estrategia de contenido que experimenta la cadena, sustituyendo a su proveedor principal de ficción televisiva (Televisa México) por las nuevas producciones que llegan desde el país otomano.

\section{Marco Teórico: Contextualización y desarrollo de la telenovela turca}

La telenovela ha sido un producto con denominación de origen propio, que ha etiquetado a las ficciones seriadas latinoamericanas desde prácticamente los orígenes de la televisión. A través de la circulación de este producto cultural, se construye una de las modalidades del imaginario latinoamericano, un espacio en el que se eliminan las fronteras y surge un discurso homogéneo, basado en una imagen unificada de lo popular (Martín-Barbero, 1992).

La telenovela latinoamericana está considerada un producto televisivo de éxito no solo por la velocidad y volumen de su exportación, sino también por las características específicas de su formato. Así pues, la telenovela permite al espectador organizar la experiencia vivida y mantener la ilusión en la superación y la resolución de problemas (González-Rubín, 2007). La telenovela es- 
tereotipa y estandariza personajes, lo que hace que su consumo sea sencillo, de fácil asimilación y enormemente expandible (Hidalgo-Marí, 2011; Lataban, 1995).

Cueva (1999) señala que la telenovela se sustenta en cuatro pilares fundamentales que son la continuidad, el melodrama, la pasión como herramienta de exaltación y la conclusión o el final feliz. Mazzioti (1996) añade que la circulación transnacional de los productos televisivos ha adquirido una volumen indiscutible debido a la serialidad, pero también al coste económico del producto, fácil de exportar y adaptar a otros países y a las distintas plataformas audiovisuales.

Mientras que la telenovela latinoamericana ha suscitado mucho interés en la comunidad académica, el fenómeno de la exportación de la telenovela turca todavía se encuentra "entre bambalinas" debido, probablemente, a su reciente éxito. No obstante, empiezan a proliferar estudios que analizan el fenómeno turco desde la producción y distribución (Cetin, 2014; Ozalpman, 2017) o desde las propias narrativas (Hudson, 2014; Kharroub \& Weaver, 2014), destacando la importancia incipiente que adquieren los estudios de género alrededor de estos productos televisivos (Ozmen, 2011).

El mercado de las series de televisión turcas está marcado por una fuerte competencia local. Según un informe de Deloitte (2014), focalizado en el país otomano, de las 60 series producidas de media cada año en el país, casi el 50\% no ejecuta más de 13 episodios, debido a la fuerte competencia entre los propios canales locales y las productoras, algo que se traduce en un índice de calidad y popularidad mayor en aquellas producciones de mayor duración.

En cuanto a su formato y duración, nos encontramos ante las producciones de ficción televisiva más largas de la historia, con capítulos que pueden durar entre 100 y 150 minutos, frente a la duración estándar de 45-60 minutos tanto para telenovelas como para en la ficción televisiva global (Hidalgo-Marí, 2018; Lacalle \& Gómez, 2016), a pesar de que empiezan a emitirse capítulos más cortos, calcando una estructura similar a la de las telenovelas latinoamericanas, con una duración que oscila entre los sesenta y los noventa minutos por capítulo. Avendaño (2019) apunta que la telenovela turca cuida más el reparto y la producción: mientras que en la telenovela latinoamericana predominan los interiores, la turca se graba, en su gran mayoría, en exteriores, huyendo del escenario de cartón piedra, acercando la producción a un estilo mucho más cuidado, más propio del cine que de la puesta en escena televisiva.

Sin embargo, a pesar del esfuerzo por recrear un escenario más cinematográfico, la calidad audiovisual no sobresale en estas producciones, así como el montaje narrativo, que en algunas ocasiones presenta limitaciones formales considerables.

Siguiendo con la tradición que define al melodrama, la telenovela turca se dirige principalmente a una audiencia femenina relatando dicotomías entre el bien y el mal, la riqueza y la pobreza, la justicia y la injusticia o el amor y el desamor, a pesar de que estudios recientes constatan la reciente aparición de temas políticos y críticas sociales (Cetin, 2014), un fenómeno que no solo se detecta en la telenovela turca, sino que es extensible a otras producciones vecinas, como el melodrama indio o egipcio (Abu-Lughod, 2002). 


\subsection{La telenovela turca en España: El caso Nova}

El consumo de telenovelas en España ha disminuido considerablemente si comparamos los datos con los de finales del siglo XX. La década de los noventa, incluso los primeros años del nuevo siglo, fueron tiempos en los que la telenovela latinoamericana tenía una posición privilegiada en las cadenas nacionales. Los estudios sobre el éxito e impacto de la telenovela en España (Chicharro-Merayo, 2011; Martín-Barbero, 1992: 47; Morales-Morante, 2008) coinciden en que son la estructura melodramática, las historias universales cotidianas, los personajes estereotípicos y los escenarios reconocibles, los factores determinantes de su buena aceptación por parte de las audiencias.

La producción española de telenovelas nunca ha tenido especial relevancia, si bien es cierto que existen ciertas producciones que han gozado de un éxito sin precedentes, como El Super (TelecinCo, 1996-1999), Amar en tiempos revueltos (TVE1, 2005-2010) o El secreto de puente viejo (Antena3, 2011-), a pesar de que sus formatos no responden estrictamente al de la telenovela, sino que se entienden como híbridos que conjugan elementos de la ficción latinoamericana con rasgos propios de la ficción seriada española (Chicharro-Merayo, 2011). Cabe destacar la apuesta autonómica por estos productos, que ha abanderado la producción propia de telenovelas, apostando además por productos de éxito exportables a otras autonomías. Por ejemplo, Poble Nou (1994) o Secrets de familia (1995), ambas producidas y emitidas por la cadena autonómica TV3.

En contraposición a la poca incidencia de la producción propia de telenovelas, desde el apagón analógico y la consolidación de la TDT, España vive una apuesta sin precedentes por la producción y emisión de series de televisión, dejando la telenovela relegada a la estrategia de la importación (Lacalle \& Gómez, 2016). En este sentido, resulta necesario estudiar el caso de la cadena temática Nova, que se posiciona como la cadena líder en emisión de telenovelas'.

Nova ha emitido un total de 112 telenovelas desde el año 2010 (ver tabla 1), de las cuales el 45\% han sido de origen mexicano, producidas por Televisa, seguidas de un $27 \%$ de telenovelas de origen estadounidense, fundamentalmente de la productora Telemundo. Frente a estos datos, destaca que el $8.9 \%$ de la emisión de telenovelas se corresponde con telenovelas turcas, un dato importante si se tiene en cuenta que la primera emisión de telenovelas turcas se realizó en enero del 2018, esto es, que en poco más de un año el mercado turco ha superado al producto importado de Venezuela (4.5\%), Argentina (1.79\%) o Brasil (0.8\%) y se sitúa casi al mismo nivel que la importación de producto colombiano (11\%).

El punto de partida de la telenovela turca en la televisión española se puede situar en el año 2018, tras el lanzamiento de la telenovela Fatmagül (2018). No obstante, un año antes, Telecinco estrenaba El accidente (Telecinco, 2017-2018), una adaptación libre del drama otomano Son (2012), que obtuvo una media del $16.3 \%$ de share con 2.608 .000 espectadores, apuntando una posible tendencia que, efectivamente, se consolida desde la irrupción de la ficción turca en las cadenas españolas. 


\begin{tabular}{lcccccccc} 
Año & $\begin{array}{c}\text { Total } \\
\text { estrenos }\end{array}$ & México & EEUU & Colombia & Venezuela & Argentina & Brasil & Turquía \\
\hline 2010 & 18 & 6 & 6 & 4 & 1 & 1 & 0 & 0 \\
2011 & 11 & 2 & 4 & 5 & 0 & 0 & 0 & 0 \\
2012 & 12 & 7 & 4 & 0 & 1 & 0 & 0 & 0 \\
2013 & 13 & 6 & 4 & 2 & 1 & 0 & 0 & 0 \\
2014 & 8 & 5 & 2 & 1 & 0 & 0 & 0 & 0 \\
2015 & 12 & 6 & 5 & 0 & 0 & 1 & 0 & 0 \\
2016 & 10 & 8 & 2 & 0 & 0 & 0 & 0 & 0 \\
2017 & 9 & 4 & 3 & 1 & 1 & 0 & 0 & 0 \\
2018 & 9 & 5 & 0 & 0 & 0 & 0 & 0 & 4 \\
2019 & 10 & 2 & 0 & 1 & 0 & 0 & 1 & 6 \\
\hline TOTAL & 112 & 51 & 30 & 14 & 4 & 2 & 1 & 10 \\
\hline
\end{tabular}

Tabla 1: Emisión de telenovelas Nova por país de origen. Fuente: elaboración propia

Tras el pistoletazo de salida de Fatmagül (Ay Yapım, 2018), la cadena estrenó tres telenovelas turcas en el mismo año Amor de contrabando (Ay Yapım, 2018), Sila (Fm Yapım, 2018) y Ezel (Ay Yapım, 2018) y seis títulos más hasta septiembre de 2019, evidenciando la apuesta firme por la telenovela otomana y posicionándose como la cadena líder en oferta de telenovelas entre todas las cadenas temáticas de la TDT española.

\section{Objetivos y metodología}

El objetivo principal del presente trabajo reside en aportar una radiografía sobre la forma y el contenido narrativo de las telenovelas turcas emitidas en España, en concreto, en la cadena temática Nova, por considerarla, según datos de audiencia², la cadena temática líder en España en lo que a la emisión de telenovelas se refiere ${ }^{3}$.

De este objetivo principal surgen otros objetivos específicos que pretenden detectar innovaciones o puntos fuertes que hayan podido contribuir a la sustitución de la telenovela latinoamericana por la telenovela turca en la cadena, a saber, nuevos estándares en la producción o en la narración que se adecuen o no a la demanda de los telespectadores y/o de la cadena. En este sentido, los objetivos específicos son:

- Conocer los estándares de producción (formatos, géneros, duración y longevidad) de las telenovelas turcas.

\footnotetext{
${ }^{2}$ Según datos ofrecidos por los Informes de Audiencias Anuales de Barlovento Comunicación, Nova mantiene un share medio del 2,2 \% anual, desde 2011, superior en $0.2 \%$ al de su principal competidora, la cadena Divinity del Grupo Mediaset, que sitúa su media anual en un $2 \%$ de share medio.
${ }^{3}$ A pesar de que el objetivo de la presente investigación está focalizado sobre la cadena Nova, no se puede pasar por alto la apues- ta por la telenovela turca que realiza la cadena temática Divinty del grupo Mediaset. Divinity, el 23 de octubre de 2018 incorporó la primera telenovela turca de su programación titulada Kara Sevda: Amor eterno, a la que siguieron Sühan: Venganza y amor, Stiletto Vendetta, Erkenci Kuş: Pájaro soñador, Kuzey Güney: Dos hermanos y un mismo amor, Amor en blanco y negro o içerde: Nada es lo que parece.
} 
- Analizar y detectar temáticas, protagonismos y entornos comunes que permitan hablar de una taxonomía común.

- Detectar diferencias y similitudes entre el drama otomano y la ficción latinoamericana con el fin de establecer posibles innovaciones que han beneficiado al posicionamiento de la telenovela turca.

La metodología utilizada en el trabajo se caracteriza por aportar un método genuino que combina técnicas cuantitativas con análisis cualitativos. Para llevarlo a cabo se han seleccionado todas las telenovelas de origen turco emitidas en Nova desde su origen hasta el 30 de septiembre de 2019 y se han clasificado en una tabla de recogida creada ad hoc, donde se han registrado todos los datos relativos a control, origen, producción, formato y clasificación. Una vez realizada la clasificación de las telenovelas, todas ellas se han sometido a visionado y clasificación, atendiendo a las siguientes variables:

- Duración: por considerarla una posible alteración de las telenovelas turcas en comparación al formato norteamericano.

- Longevidad y trayectoria: se toma como referencia el número de capítulos y temporadas de las telenovelas analizadas.

- Género y subgénero: se recoge el género temático predominante y los subgéneros en caso de detectarlos.

- Temática predominante: se recoge el conflicto que da lugar al desarrollo de la telenovela.

- Temáticas secundarias: se recogen los conflictos secundarios que engloban a la estructura dramática predominante.

- Entorno y localización: se indica el lugar geográfico predominante en el que se desarrolla la acción dramática y el entorno (rural, ciudad...) en el que sucede la acción.

- Protagonismo: se indica si el protagonismo es coral o si se detectan mayores protagonismos femeninos y/o masculinos.

- Antagonismo: se indica si el antagonismo es coral o si se detectan mayores protagonismos femeninos y/o masculinos.

- Franja de emisión: se analiza la inclusión de las ficciones en las distintas franjas horarias de la parrilla televisiva (day time, mediodías, sobremesas, acces prime time y prime time) para valorar la relación existente entre las audiencias y la franja horaria en la que se emite.

La muestra a analizar se compone de las diez telenovelas de origen turco emitidas en la cadena Nova en España hasta el 31 de septiembre de 2019 (ver tabla 2). 


\begin{tabular}{lcccccc} 
Titulo & Productora & Día & $\begin{array}{c}\text { Fecha estreno } \\
\text { (Nova) }\end{array}$ & Temp. & Cap. & Género \\
Fatmagul & Ay Yapım & L-M-X-J-V & $08 / 01 / 2018$ & 2 & 80 & Drama \\
Amor de contrabando & Ay Yapım & L-M-X-J-V & $28 / 05 / 2018$ & 2 & 54 & Drama \\
Sila & Fm Yapım & L-M-X-J-V & $28 / 11 / 2018$ & 3 & 79 & Drama \\
Ezel & Ay Yapım & L-M-X-J-V & $10 / 09 / 2018$ & 2 & 71 & Drama \\
Medcezir & Ay Yapım & L-M-X-J-V & $21 / 01 / 2019$ & 2 & 77 & Drama \\
Madre & Med Yapım & L-M-X-J-V & $24 / 03 / 2019$ & 1 & 33 & Drama \\
El secreto de Feriha & Med Yapım & L-M-X-J-V & $29 / 04 / 2019$ & 2 & 67 & Drama \\
Elif & Green Yapım & L-M-X-J-V & $13 / 05 / 2019$ & 5 & 940 & Drama \\
Amor prohibido & Ay Yapım & L-M-X-J-V & $24 / 06 / 2019$ & 2 & 79 & Drama \\
Las mil y una noches & TMC Film & L-M-X-J-V & $15 / 09 / 2019$ & 3 & 90 & Drama \\
\hline
\end{tabular}

Tabla 2: muestra de telenovelas de origen turco emitidas en Nova. Fuente: elaboración propia.

\section{Resultados}

\subsection{Formatos y producción de la telenovela turca}

Las telenovelas turcas emitidas en Nova se caracterizan por presentar una duración dilatada de los capítulos, en comparación a la duración preestablecida de la telenovela latinoamericana y la española. Tradicionalmente, la telenovela latinoamericana, en concreto la de producción mexicana, se ha caracterizado por tener una duración alrededor de los 30 minutos (Cabrujas, 2002) o la telenovela brasileña, que se posiciona entre 30 y 50 minutos por capítulo (Figaro, 1997: 96). La telenovela turca, por su parte, presenta un modelo de producción distinto, centrado en la larga duración de los capítulos, que, como mínimo se apoyan en el patrón de los 90 minutos. Si bien es cierto que más de la mitad de las telenovelas emitidas en Nova responden a esta duración (6 de 10 casos), es necesario destacar la presencia de duraciones mayores: por ejemplo, los casos de Medcezir, Madre o El secreto de Feriha, presentan una duración mucho mayor, superando los 120 minutos por capítulo. El ejemplo de Elif es la excepción en esta variable puesto que sus capítulos tienen una duración de alrededor de 60 minutos, a pesar de que siguen siendo más largos que la media estándar latinoamericana. Cabe mencionar que la duración inferior de Elif puede verse justificada por la duración global de la telenovela, que supera los 900 capítulos en cinco temporadas. y su naturaleza diaria, a diferencia del resto de telenovelas mencionadas, que están diseñadas para su emisión semanal.

En cuanto a su longevidad, no se puede considerar las telenovelas excesivamente largas, si bien es cierto que lo habitual es que tengan una duración que oscile entre los 60 y los 90 capítulos, como constatan 8 de los 10 casos analizados. Según Quispe Agnoli (2009: 3) "la telenovela [latinoamericana] suele tener entre 180 y 200 episodios y se transmiten entre tres y seis u ocho meses, aunque estas características son flexibles". Se observa, pues, que a pesar de que la duración de los capítulos es notablemente mayor, la longevidad de la telenovela turca tiene un corte temporal menor. La innovación o excepción se encuentra en la telenovela turca más corta, Madre 
(33 capítulos) y en un caso paradigmático ya mencionado, Elif, con 940 episodios en cinco temporadas, recordando a culebrones mexicanos como El amor tiene nombre de mujer (760 capítulos), Simplemente María (435 capítulos), Agujetas de color de rosa (300 capítulos) o algunas telenovelas de éxito españolas como Amar en tiempos revueltos (más de 1716 capítulos en su primera versión en RTVE) o Acacias 36 (1.114 capítulos y en emisión en el año 2019).

Un elemento innovador en la producción de la telenovela turca es la estructuración de la programación en temporadas, algo que ni la telenovela latinoamericana ni la española han aplicado en su oferta audiovisual. Tal y como se observa en el análisis, exceptuando el caso de Madre (1 temporada, debido a su escasa duración y Elif, por su longevidad), el producto turco se estructura mínimo en dos temporadas (Fatmagul, Amor de contrabando Ezel Medcezir, El secreto de Feriha y Amor prohibido) y solo Sila y Las mil y una noches se estructuran en tres temporadas. Obviamente no se trata de una apuesta decisiva por la estructura seriada de temporadas, pero permite augurar cierta hibridación en la forma, acercándose a la tendencia global alrededor de los productos seriados que, a pesar de no ser un fenómeno nuevo, se ha visto incentivada, en gran parte, por el auge de la ficción en VOD e in streaming.

En cuanto a los días y la franja de emisión, las telenovelas turcas en Nova se emiten siempre de lunes a viernes (el espacio de fin de semana está destinado a otro tipo de programación) y han copado la franja de prime time de la cadena. Todas las ficciones otomanas han sido emitidas en dicha franja, si bien es cierto que algunas como Sila o Ezel, por su coincidencia en antena con otros productos turcos, se han visto desplazados al acces prime time. En cualquier caso, la ficción turca ocupa un lugar privilegiado en lo que a la franja de emisión se refiere, respondiendo a la lógica estratégica de la programación televisiva latinoamericana, en la que la telenovela se emite en "prime time donde se redime la comunicación familiar" (Orozco, 2006: 12) frente a la tendencia española a emitir la telenovela en la franja de sobremesa/tarde y reservar el prime time para productos de ficción nacional (Quispe Agnoli, 2009: 7).

\subsection{Tramas y narraciones}

El único género detectado en las telenovelas turcas emitidas por Nova es el género dramático. Todas las ficciones hacen alusión al género canónico, debido, en parte, a la herencia latinoamericana pero también a la propia naturaleza de la telenovela. En cuanto a las tramas narrativas, la telenovela turca presenta un escenario innovador en relación con las telenovelas latinoamericanas, si se tiene en cuenta que las temáticas principales buscan conflictos y escenas más exóticas y de suspense. La telenovela latinoamericana "como subgénero particular dentro del melodrama, presenta algunas particularidades narrativas. Dramatiza, sobre todo, las dificultades y conflictos románticos, de ahí que suela estructurar su trama principal en torno a un triángulo amoroso" (Chicharro-Merayo, 2011: 190). En la telenovela turca se detecta que el conflicto amoroso, el triángulo o la lucha por el amor imposible están presentes. Sin embargo, en los casos analizados, suele desarrollarse como trama principal acompañada de tramas paralelas más enfocadas al suspense, la acción o la recreación de conflictos exóticos y ajenos a la dicotomía de amor/desamor. 
No obstante, merece la pena detenerse en aquellas telenovelas en las que el subgénero se aleja del romance. Amor de contrabando, por ejemplo, representa un drama próximo a la intriga, con detalles propios del thriller psicológico y de la narrativa de suspense. La telenovela cuenta las vivencias de un agente de policía que, tras encontrar el cadáver de su prometida junto al cadáver de un empresario poderoso, iniciará una investigación para esclarecer los motivos del crimen. En el desarrollo, el protagonista se relacionará con la hija del empresario asesinado, desarrollando una trama personal a lo largo de la historia. Se trata de una narración cargada de investigación, de debate moral, de deontología, pero también de misterio, incógnitas y subtramas exóticas que alimentan el relato. El drama amoroso existe y forma parte de la línea conductora del diálogo narrativo, pero no es la trama principal. Se está, pues, ante una innovación narrativa más próxima a lo que Acosta-Alruzu (2003) denominó "telenovelas de ruptura" que al paradigma narrativo tradicional de la telenovela latinoamericana.

Algo similar ocurre con la telenovela Medzedir que, a pesar de haber estado catalogada por algunos repositorios como drama juvenil, presenta gran variedad de temas alejadas del conflicto amoroso. En Medzedir, la delincuencia, las problemáticas juveniles (adicciones, drogas, fiestas, inconformismo y redes sociales, entre otras) es un hecho, pero también lo son temáticas derivadas de la desigualdad social, la diferencia de clases y los conflictos de poder. Además, la serie introduce el debate sobre los prejuicios sociales, la hipocresía o la importancia del dinero como clave de poder. La trama amorosa aparece a medida que avanza la narración, no es un elemento presente desde el comienzo de la telenovela, a pesar de que en los últimos episodios adquiere mucha importancia. A pesar de ello, la importancia es coral, es decir, convive con la trama social, con el discurso de clases y los conflictos del personaje principal, por lo que, de nuevo, se detecta el intento innovador de modificar la lógica narrativa tradicional de la telenovela.

El caso de Ezel conjuga la narración amorosa con una narración propia de los productos de acción. En la telenovela, los robos, la corrupción, el engaño o la traición adquieren posiciones privilegiadas, unidas a escenarios carcelarios, suburbios y ambientes más propios del cine de acción que de una telenovela. El drama amoroso existe y supone una narración importante, pero, al igual que ocurre en Medzedil, aparece cuando la narración principal, la que supone el detonante de la historia, ya está avanzada.

A pesar de que se detectan innovaciones significativas en las narraciones, el resto de los casos analizados revive el paradigma amoroso como punto de partida, punto de inflexión y final, apostando por la estructura tradicional, el final feliz y el castigo de los villanos. Amor, desamor, conflictos de intereses, conflictos familiares, lucha de clases y amores imposibles por esferas económicas distintas son núcleos narrativos presentes, heredados de la telenovela latinoamericana. Sin embargo, se introducen muchas más cuestiones morales y éticas (como se aprecia, por ejemplo, en Fatmagül) que conflictos basados puramente en el amor y el desamor y la controversia entre ricos y pobres, en una apuesta más contemporánea que pretende acercarse a los conflictos y situaciones más actuales. También se introducen nuevas narrativas relacionadas con la representación de modelos familiares contemporáneos, alejando la narración principal de la dicotomía amor/desamor. La recreación de nuevos modelos familiares es un elemento directamente heredado de las tendencias en formatos ficcionales (Hidalgo-Marí, Tous-Rovirosa 
y Morales-Morante, 2019; Lacalle e Hidalgo, 2016), algo que no había tenido hasta el momento, demasiada incidencia en la telenovela como refleja la telenovela. Este hecho se constata en la narración de la telenovela Madre, en la que la trama principal se desenvuelve en la relación familiar de la protagonista y una de sus alumnas a la que adopta tras descubrir que sufría maltratos en su núcleo familiar. También se aprecian innovaciones en el relato de Las mil y una noches, al introducir modelos familiares desestructurados y temáticas latentes como son la prostitución, la lucha frente a enfermedades y los conflictos éticos sociales, sin perder de vista, eso sí, el costumbrismo y la doble moral canónica que desprenden los papeles de los protagonistas.

Un elemento interesante sobre la estructura narrativa es el punto de acción. Siguiendo con la forma de proceder de la serie convencional, cada capítulo presenta un punto de inflexión, un elemento de acción que provoca esa necesidad sobrevenida de la propia serialidad. La telenovela latinoamericana, según expone Gallardo (2009), era mucho más lenta, y la acción dramática se desarrollaba cada seis u ocho capítulos. El drama otomano se asemeja más a las producciones norteamericanas o europeas de ficción, en las que cada capítulo debe contener su propio núcleo dramático de acción.

Si se pormenoriza en los detalles de las narraciones se observa que la telenovela turca está ambientada, esencialmente, en Estambul, un hecho que se justifica por la necesidad de las empresas productoras de desplazarse a la ciudad tras la liberación de la televisión privada turca en los años 90. Por cercanía y atendiendo al juego que aporta la propia estética de la ciudad, proliferan las grabaciones en exterior, algo distinto a lo que ocurría en la telenovela latinoamericana en la que predominaban los relatos recreados en interior. Todos los casos analizados se desarrollan en un entorno cosmopolita, de ciudad, alejándose de los escenarios rurales que han caracterizado, durante décadas, el contexto de la telenovela latinoamericana. Los escenarios rurales, cuando aparecen, suelen utilizarse como refugios de huida, idílicos, donde muchas veces se desarrolla la relación romántica de los personajes. Así, son relatos mucho más actuales, enmarcados en los problemas y conflictos de la ciudad, que apuestan por una recreación de relatos reales, vivos y coetáneos con el espectador. Sin embargo, a pesar de que los relatos se desarrollan en el contexto de la ciudad, se debe tener en cuenta que se trata de escenarios exóticos que mantienen la esencia cultural de la historia que sustentan y, por ende, se consigue el doble objetivo: ambientar los problemas y relatos en un escenario mucho más contemporáneo, alejándolo del imaginario rural pero, a su vez, mantener esa vinculación con el mundo exótico y desconocido para las audiencias transnacionales, que supone uno de los puntos clave de la configuración de la telenovela turca. Como caso excepcional, destaca la apuesta por un escenario mucho más rural en la telenovela Sila, en la que la protagonista vuelve a Mandin, su ciudad de origen, a buscar sus verdaderas raíces y parte de la historia se desarrolla en esta ciudad más rural, en un guiño a los escenarios convencionales que han suscitado interés alrededor de las telenovelas latinoamericanas.

\subsection{Configuración de los personajes}

En cuanto a la configuración de los personajes, se detecta que existe un protagonismo mayor de 
las mujeres que de los hombres si se habla de personajes principales. En cinco de los diez casos de análisis la mujer es la que desarrolla la trama principal de la historia y a su alrededor se recrean los conflictos paralelos que alimentan la narración principal. Este protagonismo femenino viene condicionado por el reflejo de un personaje femenino todavía dependiente: El secreto de Feriha, por ejemplo, muestra cómo una mujer es capaz de inventar toda su vida para ser aceptada por un grupo de clase social más alta o Sila, que se ve obligada a casarse de forma comprometida y sin desearlo para salvar la vida de su hermano. En Amor prohibido, la protagonista, a pesar de pertenecer a una clase privilegiada y vivir rodeada de lujos, está sometida al control de los hombres y poco puede hacer para escapar.

Cuando los hombres son los protagonistas de las narraciones otomanas, son aventureros, valientes y poderosos, capaces de todo para conseguir sus objetivos, como se constata en Ezel o Medzedir, en las que los hombres, con más o menos recursos, se representan capaces de salir y superar cualquier situación mientras que la representación de las mujeres sigue siendo hegemónica y dependiente de la figura del hombre.

En la construcción narrativa de los personajes se detecta que se juega al intercambio de roles: los buenos pueden ser malos y los malos se pueden convertir en buenos. Se trabaja mucho la psicología del personaje, de tal forma que los villanos simpatizan con el espectador y los buenos proponen debates morales que cuestionar.

\section{Conclusiones}

Tras la exposición de los resultados de los análisis realizados, se puede afirmar, en primer lugar, que la telenovela turca es un producto narrativo que, a pesar de mantener muchos elementos en común con la producción latinoamericana, se define a ella misma como innovadora, gracias a la apuesta por nuevos elementos, de formato y producción, pero también narrativos que configuran un producto con sello de identidad propio.

No se habla solamente de denominación de origen y cambios culturales que afecten al imaginario audiovisual del producto de ficción, sino de algo mucho más arriesgado: la apuesta por un formato híbrido, que conjuga los valores más arraigados a la telenovela latinoamericana con rasgos distintivos de las grandes producciones de las series de televisión internacionales; una combinación que se puede considerar como un subgénero híbrido, a caballo entre la telenovela y la serie, entre la ficción más tradicional y la más innovadora, una apuesta audiovisual en la que, en algunos casos, los límites quedan difusos.

Como se ha podido demostrar en el apartado de resultados, la telenovela turca apuesta por capítulos mucho más largos y estructura la vida de los productos audiovisuales en temporadas, en línea a la tendencia a la ficción internacional, algo que la telenovela no había explotado, al centrarse en capítulos de corta o media duración y una única temporada. Los productos estudiados son productos longevos, con muchos capítulos de duración. Además, la exportación de la telenovela turca se postula como un producto de prime time, dejando la franja de la sobremesa al culebrón latinoamericano, una estrategia de programación televisiva que, hasta el momento, no se había llevado a cabo en España, aunque sí en los países productores latinoamericanos. 
Esta apuesta por el prime time permite vislumbrar una apuesta por la ficción otomana y una consideración de calidad, probablemente superior a la consideración que se tenía de las telenovelas latinoamericanas, si bien es cierto que la estrategia de programación viene condicionada, también, por la innovación en las temáticas y relatos. No obstante, debemos tener en cuenta que se programan telenovelas turcas en otras franjas horarias, aunque el prime time ha sido utilizado estratégicamente por la cadena en cuestión.

En cuanto a las temáticas y relatos, se concluye que la telenovela turca apuesta por temas más actuales y contemporáneos, a diferencia de la cotidianeidad y el relato rural que han perpetuado las telenovelas latinoamericanas. El suspense, la intriga, la acción tiene cabida en el drama otomano, además, de forma protagonista. Si bien es cierto que se perpetúan roles y patrones tradicionales (de género, de diferencia social, de clases sociales y/o conflictos amorosos), se vislumbra una apuesta por temáticas menos recurrentes como la lucha de clases, la ruptura con los patrones establecidos, el debate moral sobre el funcionamiento del mundo o la propia forma de concebir el amor. No se puede olvidar que, al fin y al cabo, el conflicto dicotómico entre amor y desamor sigue teniendo mucho peso, pero se ve desplazado a una posición coral para introducir tramas y relatos más propios de la ficción televisiva internacional en formato de series. Incluso temas como el narcotráfico, las mafias o la vida en las cárceles encuentran en el drama turco su espacio, algo no detectado en términos generales en la telenovela latinoamericana y que, sin embargo, es una de las tendencias actuales en la ficción televisiva internacional ( $y$, en especial, entre la nueva producción de ficción in streaming y VOD).

En cuanto a los personajes, se ha detectado que sigue existiendo una forma hegemónica de representar a las mujeres dependientes del hombre. A pesar de que en muchos de los dramas turcos la mujer es la protagonista, sus posibilidades de empoderamiento están mermadas por la sociedad que sustenta el relato. Los roles representados siguen marcados por una sociedad desigual y la construcción social femenina sigue la fórmula de representación del drama latinoamericano. No obstante, como matiz, es necesario tener en cuenta cómo es la sociedad que sustenta el producto audiovisual en cuestión, a pesar de que la producción, en estos momentos, está enfocada a la exportación del producto.

Otra innovación de la telenovela turca frente a la latinoamericana es la configuración de personajes alternativos en lo que a su rol se refiere. Mientras que la telenovela latinoamericana apostaba por una configuración sólida de personajes protagonistas y antagonistas, de personajes buenos y villanos, en la ficción otomana se detecta una verosimilitud en los papeles: los buenos no son tan buenos o los malos pueden convertirse en buenos en un momento dado; una innovación de los roles temáticos que parece ser heredada de las nuevas macro producciones internacionales, en las que la construcción estética y narrativa de los villanos plantea cuestiones éticas y morales que, en algunos casos, aproximan al villano a la comprensión y la simpatía del receptor.

A modo de conclusión, nos encontramos ante un producto audiovisual innovador, que conjuga elementos tradicionales de la telenovela latinoamericana con rasgos en formato y en contenido propios de las grandes producciones de ficción audiovisual (no telenovela). Esta conjugación se ha convertido en un producto muy demandado por los públicos y por las cadenas, hasta el punto de que muchas de ellas han bifurcado su oferta programática hacia el drama turco. La 
hibridación que caracteriza a este nuevo producto audiovisual permite dotarlo de un sello de autenticidad propio, una nueva forma de entender la telenovela, alejándola de los patrones clásicos, tradicionales y acercándola a una esfera más actual, más contemporánea que responde a las necesidades y reclamos de la audiencia consumidora.

\section{Referencias bibliográficas}

ABU-LUGHOD, Lila (2002): “Egyptian Melodrama: Technology of the Modern”, en Media worlds: Anthropology on new terrain, no 21, pp. 75-102. doi: http://dx.doi.org/10.1590/S0104-83332003000200005

ACOSTA-ALRUZU, Carolina (2003): “I am Not a Feminist... I Only Defend Women as Human Beings: The Production, Representation, Consumption of Feminism in a Telenovela", en Critical Studies in Media Communication, no 20(3), pp. 269-249.

doi: https://doi.org/10.1080/07393180302775

AKIN, Altug (2009): “Dirty Seeds of Media Transformation in Turkey: The Vertigo of Communication, the Young Party (Genc Parti) and the Democratic Deficit", en Eastbound (2). Recuperado de http://eastbound.eu/2010/akin

AKIN, Altug (2011): “Cuando se abre la caja mágica de Pandora. Desarrollo de los medios en Turquía", en Infoamérica: Iberoamerican Communication Review, no 6,pp. 97-114. Recuperado de https://bit.ly/2BVe5bh

AVENDAÑO, Tom C. (2019): "Las telenovelas turcas conquistan España”, en El País, 22 de febrero. Recuperado de https://bit.ly/2KLefqw

BALLI, Faruk, BALLI, Hatice O. \& CEBECI, Kemal (2013): “Impacts of exported Turkish soap operas and visa-free entry on inbound tourism to Turkey", en Tourism Management, no 37, pp. 186192. doi: https://doi.org/10.1016/j.tourman.2013.01.013

BARLOVENTO COMUNICACIÓN (2019): "Análisis televisivo 2018". Recuperado de https:// bit. ly/2NqVEAD

CABRUJAS, José Ignacio (2002): Y Latinoamérica inventó la telenovela. Caracas: Alfadil Ediciones.

CAMILLE FERREIRA, Gabrielle (2018): "O resgate do melodrama: uma análise do interesse das telespectadoras brasileiras", en Congreso COMUNICON 6o Simposio Internacional. Recuperado de https://bit.ly/32NmVTC

CETIN, Emre (2014): "The "Politicization" of Turkish Television Dramas", en International Journal of Communication, no 8, pp. 2462-2483. Recuperado de https:// bit.ly/36iaDFK

CHICHARRO-MERAYO, María del Mar (2011): "Historia de la telenovela en España: aprendizaje, ensayo y apropiación de un género", en Comunicación y Sociedad, no 24(1), pp. 189-216.

Recuperado de https://bit.ly/2N24tlG 
CUEVA, Álvaro (1999): Lágrimas de cocodrilo: historia mínima de las telenovelas en México. México: Tres Lunas.

DELOITTE (2014): “World's most colorful screen. TV series sector in Turkey". Recuperado de https://bit.ly/2JAOpFi

FIGARO, Roseli A. (1997): “La telenovela brasileña en el mercado internacional”, en Estudios sobre las Culturas Contemporáneas, no3(6), pp. 33-47.

GALLARDO, Francisco A. (2019): "Turquía se ha reencontrado con la esencia de las telenovelas", en Diario de Sevilla, 10 de febrero. Recuperado de https://bit.ly/2Wut5GK

GONZÁLEZ-RUBÍN, Beatriz (2007): "La telenovela como fenómeno social”, en Congreso Latinoamericano de Investigadores de la Comunicación (Monterrey). Recuperado de: https:// goo.gl/Cj8uso

HIDALGO-MARÍ, T. (2011). El castigo de la mujer antagonista en las telenovelas: estandarización y conservadurismo en el desenlace fatal. En Mateos-Martín, C., Ardèvol-Abreu, A. y ToledanoBuendía, S. (Coords.), La comunicación pública, secuestrada por el mercado (p. 33). La Laguna: Sociedad Latina de Comunicación Social.

HIDALGO-MARÍ, T. (2018). La comedia familiar española desde la apertura del mercado televisivo hasta el apagón analógico: Formatos, audiencias y producción (1990-2010). Comunicación y Sociedad, 31(2), 39-50. doi: https://doi.org/10.15581/003.31.2.39-50

HIDALGO-MARÍ, Tatiana; TOUS-ROVIROSA, Anna. \& MORALES-MORANTE, Luís. F. (2019): “Los modelos familiares en la comedia televisiva española (1990-2010)", en Revista Latina de Comunicación Social, no 74, pp. 1-11. doi: https://doi.org/10.4185/RLCS-2019-1318

HUDSON, Leila (2014): “Neopatriarchy in Syrian and Turkish Television Drama: Between the Culture Industry and the Dialect Imagination". en Media Evolution on the Eve of the Arab Spring (pp. 127-138). Palgrave Macmillan, New York.

KHARROUB, Tamara \& WEAVER, Andrew. J. (2014): “Portrayals of women in transnational Arab television drama series", en Journal of Broadcasting \& Electronic Media, no 58(2), pp. 179195. doi: https://doi.org/10.1080/08838151.2014.906434

LACALLE, Charo \& GÓMEZ, Beatriz (2016): "The representation of workingwomen in Spanish television fiction", en Comunicar, no 24(47), pp. 59-67. doi: https://dx.doi.org/10.3916/C472016-06

LACALLE, Charo y HIDALGO-MARÍ, Tatiana (2016): “La evolución de la familia en la ficción televisiva española" en Revista Latina de Comunicación Social, no 71, pp. 470-483. doi: https://doi.org/10.4185/RLCS-2016-1105

LATABAN, Ant (1995): Consumo de telenovelas por estudiantes de universidades privadas. Mexico Puebla: Universidad de las Américas Puebla.

MARTÍN-BARBERO, Jesús (1992): Televisión y Melodrama. Bogotá: Tercer Mundo Editores. MAZZIOTI, Nora (1996): La industria de la telenovela. La producción de ficción en América Latina. Barcelona: Paidós 
MOLINA, Lucía (2013): "El papel de la ficción televisiva en la situación sociolingüística del árabe", en RAEL: revista electrónica de lingüística aplicada, no 12, pp. 101-110.

Recuperado de https://bit.ly/2Pv10T7

MORALES-MORANTE, Luís F. (2008): “Telenovela latinoamericana en España: Identidades culturales y confluencias comerciales", en Chasqui. Revista Latinoamericana de Comunicación, no 104, pp. 52-59. Recuperado de https://bit.ly/31Xd4dn

OROZCO GÓMEZ, Guillermo (2006): “La telenovela en México: ¿de una expresión cultural a un simple producto para la mercadotecnia?", en Comunicación y Sociedad, no 6, pp. 11-35. https:// bit.ly/2X9EI68

OZALPMAN, Deniz (2017): “Transnational Viewers of Turkish Television Drama Series”, en Transnational Marketing Journal, no 5(1), pp. 25-43. doi: https://doi.org/10.33182/tmj.v5i1.386 OZBEK, Meral (1991): Popüler Kültür ve Orhan Gencebay Arabeski. Estambul: Iletisim.

OZMEN, Seckin (2011): “Global Culture And The Representation Of Otherhood In A Popular Turkish Television Drama", en International Journal of Arts \& Sciences, no 4(24), pp. 143. Recuperado de https://bit.ly/2qFaoED

QUISPE AGNOLI, Rocío. (2009): “La telenovela latinoamericana frente a la globalización: Roles genéricos, estereotipos y mercado", en Revista Académica La Mirada de Telemo, no 2. Recuperado de https://bit.ly/2XE29oF

STOKES, Martin (1992): The Arabesk Debate: Music and Musicians in Modern Turkey. Oxford: Clarendon Press. 